\title{
Nível de conhecimento e hábitos de hidratação dos estagiários de odontologia de uma instituição de ensino privado de Rondônia
}

\author{
Level of knowledge and habits of hydration of dentistry interns at a Rondônia private \\ educational institution
}

Nivel de conocimientos y hábitos de hidratación de los estudiantes de odontología en una institución de educación privada en Rondônia

Nicolas Pereira de Brito ${ }^{1 *}$, Aryane Maria Oliveira Araujoㄹ, Flávio José Esparo Coelho Júnior ${ }^{1}$, Guilherme Lopes Reis ${ }^{1}$, Giulia Giovanna Bertoldo Dantas ${ }^{1}$, Isabelle Giacomett de Carvalho Domingos e Silva ${ }^{1}$, Lara Graziela Fernandes Maia de Medeiros ${ }^{1}$, Lilian Kelly Sena dos Santos ${ }^{1}$, Victor Serrate Capucce ${ }^{1}$, Arlindo Gonzaga Branco Junior².

\section{RESUMO}

Objetivo: Correlacionar a rotina de hidratação e o nível de conhecimento dos estagiários de odontologia de uma instituição de ensino privado de Rondônia com as suas consequências. Métodos: Pesquisa quantitativa realizada no segundo semestre de 2020 em uma instituição de ensino privado de Porto Velho/Rondônia. Os dados foram levantados por meio da aplicação de um questionário envolvendo 50 estagiários do curso de Odontologia, matriculados entre o sexto e oitavo período. Resultados: Constatou-se que em relação à ingestão de água, 50\% dos estagiários alegaram beber entre 1 litro e 1,5 litro do líquido por dia, abaixo da recomendação da OMS que indica, no mínimo, dois litros de reposição hidroeletrolítica, e quando questionados sobre os motivos do esquecimento da hidratação, os participantes alegaram, majoritariamente, que a carga de trabalho seguida por momentos de pausa reduzidos, são a principal causa. Conclusão: Apesar de grande parte dos entrevistados conhecerem a importância da hidratação, a maioria não a realiza de forma adequada. Nesse sentido, o problema não está na falta de conscientização, mas sim na falta de conhecimento sobre as consequências da desidratação e o dano que isso pode ocasionar.

Palavras-chave: Hábitos, Hidratação, Odontologia.

\begin{abstract}
Objective: Correlate the hydration routine and level of knowledge of dentistry interns at a Rondônia private educational institution with its consequences. Methods: Quantitative research, realized in the second semester of 2020 at a private institution from Porto Velho, Rondônia. The data were collected through the application of a questionnaire involving 50 trainees of the dentistry course, enrolled between the sixth and eighth term. Results: It can be seen that about the ingestion of water $50 \%$ of the interns claimed to drink between 1 and 1,5 liter of liquid per day, below the OMS recommendation that indicates at least three liters of electrolyte replacement, hydration. When asked about the reasons for forgetting hydration, the participants mostly claimed that the workload followed by reduced pause moments is the main cause. Conclusion: Although most of the interviews know the importance of hydration, most do not perform properly. In that way, the problem is not in the lack of awareness, but rather in the lack of knowledge about the consequences of dehydration and the damage, it can cause.
\end{abstract}

Key words: Habits, Hydration, Dentistry.

${ }^{1}$ Centro Universitário São Lucas (UNISL), Porto Velho - RO. *E-mail: nicolaspbrito15@gmail.com

2 Universidade Federal de Rondônia (UNIR), Porto Velho - RO. 


\section{RESUMEN}

Objetivo: Correlacionar la rutina de hidratación y el nivel de conocimiento de los internos dentales en una institución de educación privada en Rondônia con sus consecuencias. Métodos: Investigación cuantitativa realizada en el segundo semestre de 2020 en una institución educativa privada en Porto Velho/Rondônia. Los datos fueron recolectados mediante la aplicación de un cuestionario en el que participaron 50 pasantes del curso de Odontología, matriculados entre el sexto y eloctavo período. Resultados: Se encontró que en relación al consumo de agua, el 50\% de los internos afirmaron beber entre 1 litro y 1,5 litros del líquido por día, por debajo de la recomendación de la OMS que indica, al menos, dos litros de reposición hidroelectrolítica, y Cuando se les preguntó acerca de las razones para olvidar la hidratación, los participantes afirmaron principalmente que la carga de trabajo seguida de momentos de pausa reducidos es la causa principal. Conclusión: A un que la mayoría de los encuestados conoce la importancia de la hidratación, la mayoría no lo hace correctamente. En este sentido, el problema no es la falta de conciencia, sino el desconocimiento sobre las consecuencias de la deshidratación y el daño que puede ocasionar.

Palabras clave: Hábitos, Hidratación, Odontología.

\section{INTRODUÇÃO}

A água é um componente essencial à vida humana e por ser o principal e o mais abundante constituinte do organismo, desempenha diversas funções orgânicas que produzem influência direta no estado de saúde de cada indivíduo (INSTITUTO DE HIDRATAÇÃO E SAÚDE, 2010).

Em vista disso, participa de inúmeras atividades fundamentais, como a manutenção do volume plasmático, agindo especialmente na regulação da temperatura corporal, no transporte de nutrientes e na eliminação de substâncias não utilizadas pelo organismo, além de participar ativamente de sistemas como o digestório, respiratório, cardiovascular e renal (CARVALHO APL e ZANARDO VPS, 2010). Assim sendo, é muito importante que o nível de água esteja adequado ao padrão fisiológico, para que as mencionadas funções sejam efetuadas de forma plena, mantendo a homeostasia corporal adequada.

Nesse contexto, considerando o corpo humano como uma ferramenta de sobrevivência quase perfeita, para que esse nível de água corporal se mantenha satisfatório e trabalhando a favor do bom funcionamento do organismo, existe o centro da sede no hipotálamo que também é a região que regula o controle do ADH (hormônio antidiurético), no qual receptores induzidos por aumento de pressão osmótica estimulam a ingestão de água e associados ao mecanismo osmorreceptor-ADH contribuem para a hidratação e consequente controle de excreção e retenção de água do organismo. Todavia, há algumas situações exógenas que interferem nesse mecanismo e podem diminuir esse consumo e resultar em uma baixa hidratação, tais como: frio, ocupações laborais, exercícios intensos e entre outras situações (TORTORA GJ e DERRICKSON B, 2010).

Considerando esse contexto, é importante ressaltar a sede como importante indicador do possível funcionamento do corpo no quesito hidratação, assim como no quesito saúde-doença. Sendo fator fisiológico, a sua falta pode indicar problemas no circuito neuroendócrino e o seu excesso pode indicar doenças como diabetes, mellitus ou insípida. Ainda assim, o consumo de água deve ser feito aos poucos durante o dia, caso contrário, uma ingestão de água de forma súbita pode ocasionar quadros extremos de intoxicação, coma ou mesmo morte (DAVANZO GG, et al., 2015).

Todos esses mecanismos convergem para a manutenção do balanço hídrico e da homeostasia. O balanço hídrico é a diferença entre a ingestão de água, por meio de alimentos, bebidas ou líquidos produzidos pelo organismo, e a água eliminada pelos processos corporais (SOCIEDADE BRASILEIRA DE ALIMENTAÇÃO E NUTRIÇÃO, 2016).

Nessas proporções que diferenciam cada corpo e sua necessidade particular de água, ainda há pessoas que precisam dessa ingestão de forma regular a independer do centro de sede do hipotálamo, como os bebês, os atletas, idosos e pessoas enfermas. Os bebês por precisarem de auxílio para ingerir os níveis adequados 
de água por dia, os atletas por terem corpos de alto rendimento e metabolização, sendo a água importante fator em ambas as funções, além de terem perda hidroeletrolítica acima da população média o que exige um nível de hidratação, também, acima da média, os idosos por perderem água fisiologicamente e os enfermos, pelas muitas doenças que acometem órgãos importantes no funcionamento da excreção, retenção e circulação de água no organismo (ROSADO Cl, et al., 2010).

As consequências, em razão disso, para aqueles que ignoram essas recomendações é a desidratação, processo de perda de água corporal sem reposição adequada, podendo ser subdividida em desidratação hipertônica, quando acontece por perda de água pura ou fluido hipotônico, isotônica, ocorrendo quando a perda por meio de fluidos com a mesma osmolalidade do fluído extracelular, e hipotônica que resulta da perda de fluido hipertônico (SHIRREFFS SM, 2003).

Essa desregulação hídrica pode ocasionar diversas consequências ao corpo. Em razão das características geográficas do Brasil, na maior parte do país predomina condições de alto estresse térmico, o que aumenta os riscos de ocorrer desidratação, além de outras doenças relacionadas ao calor (CRUZ MAE, et al., 2009).

Baseado nessa premissa, um dos grupos a serem investigados quanto a nível de importância da hidratação são os estagiários das mais diversas áreas do conhecimento, devido a sua rotina de estudos e trabalho. Pensando nisso, o presente artigo investigou o nível de conhecimento e hábitos de hidratação de alunos de um curso de odontologia de uma instituição de ensino privada do norte do país e traçar uma intervenção baseado no resultado.

\section{MÉTODOS}

Trata-se um estudo observacional, transversal, descritiva de avaliação quantitativa realizada no segundo semestre de 2020 em uma instituição de ensino privado da cidade de Porto Velho, Rondônia. O projeto foi desenvolvido por alunos no decorrer do semestre letivo de 2020-2 no 4ํㅜㅇóodo de medicina da Universidade privada de Porto Velho, em uma disciplina intitulada Projeto Integrador IV. A disciplina de Projeto Integrador IV tem como objetivo principal o aprendizado baseado em projetos, integrando a escola junto a comunidade por meio de intervenções em saúde, principalmente voltados a medicina de família e comunidade com foco na educação e promoção em saúde.

Baseado nessa premissa, o grupo se reuniu durante quatro vezes até a decisão do tema principal., utilizando para a análise posterior o diário de discussão, onde poderiam retornar as reflexões anteriores até findar um objetivo geral de comum acordo. Após quatro reuniões, decidiu-se trabalhar práticas educacionais voltadas a hidratação de estagiários que estão no campus da unidade. Decorrente a pandemia COVID - 19 e a diminuição de estágios no campus de saúde optou-se por realizar a pesquisa com estagiários de apenas um curso do campus de saúde, a fim de diminuir aglomeração no campus decorrente a pesquisa. Optou-se pelo curso de odontologia devido a rotina de estágio (integral) e número de estagiários (110 alunos ao todo).

A pesquisa envolveu estagiários do curso de Odontologia que estavam matriculados no último ano da graduação (sexto, sétimo e oitavo período) que aceitarem participar da pesquisa e assinassem o TCLE. O Universo total amostral foi de 110 alunos com a aderência de 50 alunos na presente pesquisa. Quanto ao objeto de pesquisa o questionário foi divido Conhecimento e hábitos de hidratação totalizando 7 perguntas múltipla escolha e 1 discursiva. Os dados coletados foram registrados em um banco de dados do programa Microsoft Excel 2013 e os resultados apresentados de modo descritivo no Microsoft Word 2013 analisando a frequência percentual de cada resultado. Esta pesquisa foi aprovada pelo Comitê de Ética e Pesquisa sob o número do CAAE 37153620.0.0000.0013, número do parecer 4.285.733 em 18 de setembro de 2020.

\section{RESULTADOS}

Participaram da pesquisa um total de 50 estagiários, sendo $62 \%$ mulheres $(n=31)$ e $38 \%$ homens $(n=19)$. A idade média correspondeu aos 24 anos de idade, tendo a menor faixa etária representada por 25 anos e a maior por 38 anos. Analisando os períodos os quais os estagiários pertencem, $26 \%$ estão no sexto período, $32 \%$ no sétimo período, além de $42 \%$ estarem no oitavo período. 
No que se refere, ao IMC (Índice de Massa Corpórea) dos entrevistados, calculados com base na altura e peso fornecidos no questionário, e dividido nas categorias, magreza, normal, sobrepeso, obesidade e obesidade grave, $44 \%$ ficaram na faixa normal do IMC, $24 \%$ no Sobrepeso conforme exposto no (Gráfico 1).

Gráfico 1 - Índice de Massa Corpórea dos entrevistados na pesquisa, 2021.

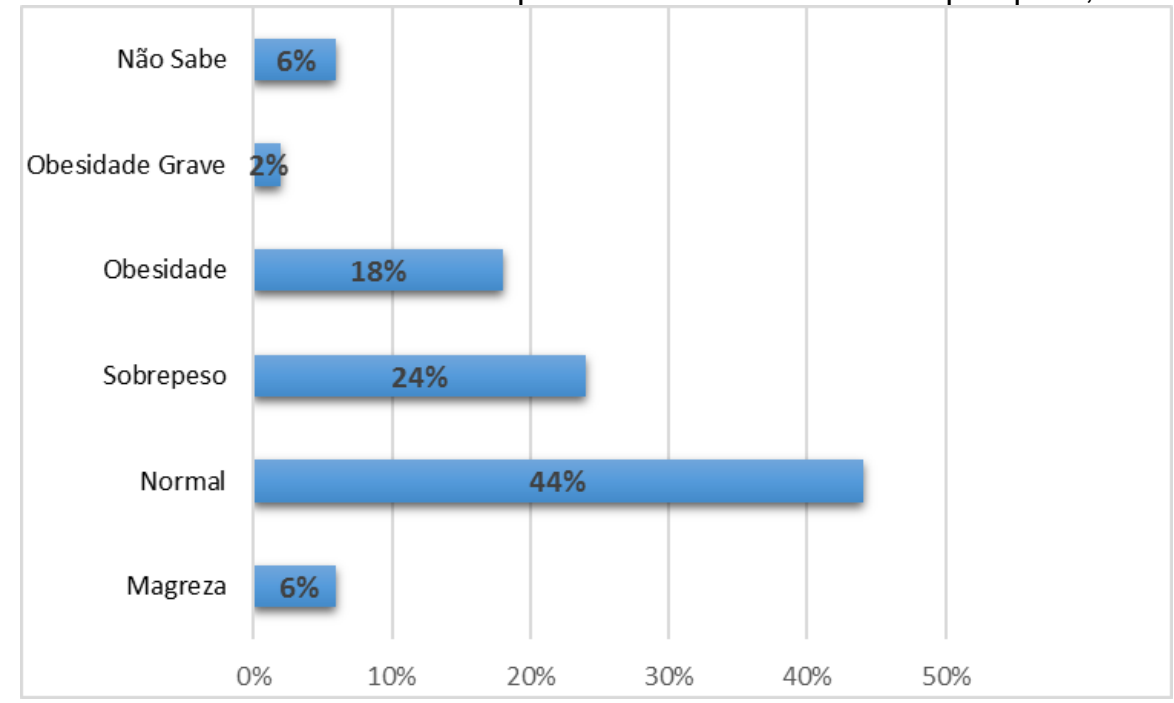

Fonte: Brito NP, et al., 2021

Em relação a quantidade média ingerida de água por dia, se obteve, os seguintes dados, $34 \%$ referiu-se ingerir 1,5 litros, 22\% (2 litros), 20\% (mais de 2 litros), 16\% (1 litro) e 2\% (Não soube responder). A frequência de ingestão dos líquidos, também foi avaliada, na qual $28 \%$ dos entrevistados relatam com uma frequência de a cada hora, $26 \%$ a cada 3 horas, $16 \%$ a cada 2 horas, $16 \%$ num intervalo maior que 3 horas e, 14\% não sabiam a frequência.

No que tange, os motivos de esquecimento da ingestão de líquido, 36\% alegaram a grande carga de trabalho. E quando, indagados acerca de quando se deve beber líquidos, $74 \%$ responderam antes da sensação da sede, $18 \%$ somente depois de sentir a sede e $8 \%$ quando se sente muita sede. Em questão de qual solução líquida tem o costume de se hidratar, 92\% mencionaram a água, 14\% Coca-Cola, 10\% sucos naturais, $8 \%$ cerveja, $6 \%$ Refrescos, $6 \%$ Café e $2 \%$ outros, lembrando que cada participante nessa questão poderia marcar mais de uma opção (Gráfico 2).

Gráfico 2 - Motivos de esquecimento da ingestão de líquidos na pesquisa, 2021

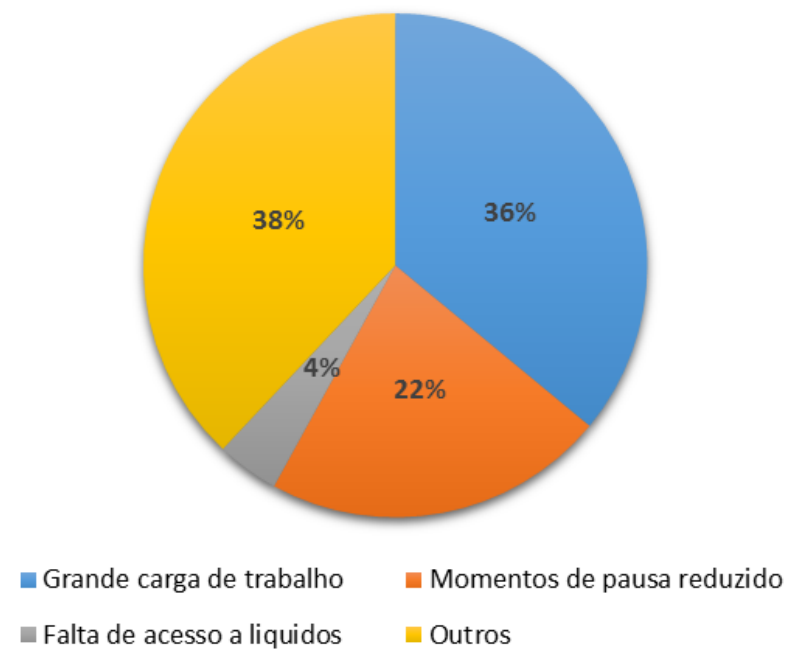

Fonte: Brito NP, et al., 2021. 
Ao avaliar a preocupação dos estagiários em relação a necessidade de se hidratar e em qual estação era mais frequente, $66 \%$ dos participantes expuseram que independia da estação, $26 \%$ no verão, $6 \%$ não se preocupava e $2 \%$ não souberam responder. Também foram questionados sobre sintomas que já apresentaram durante períodos com pouca ingestão de líquidos, $76 \%$ mencionaram sede, $74 \%$ boca seca e pegajosa (Gráfico 3).

Gráfico 3 - Sintomas por pouca ingestão de líquidos durante período longo

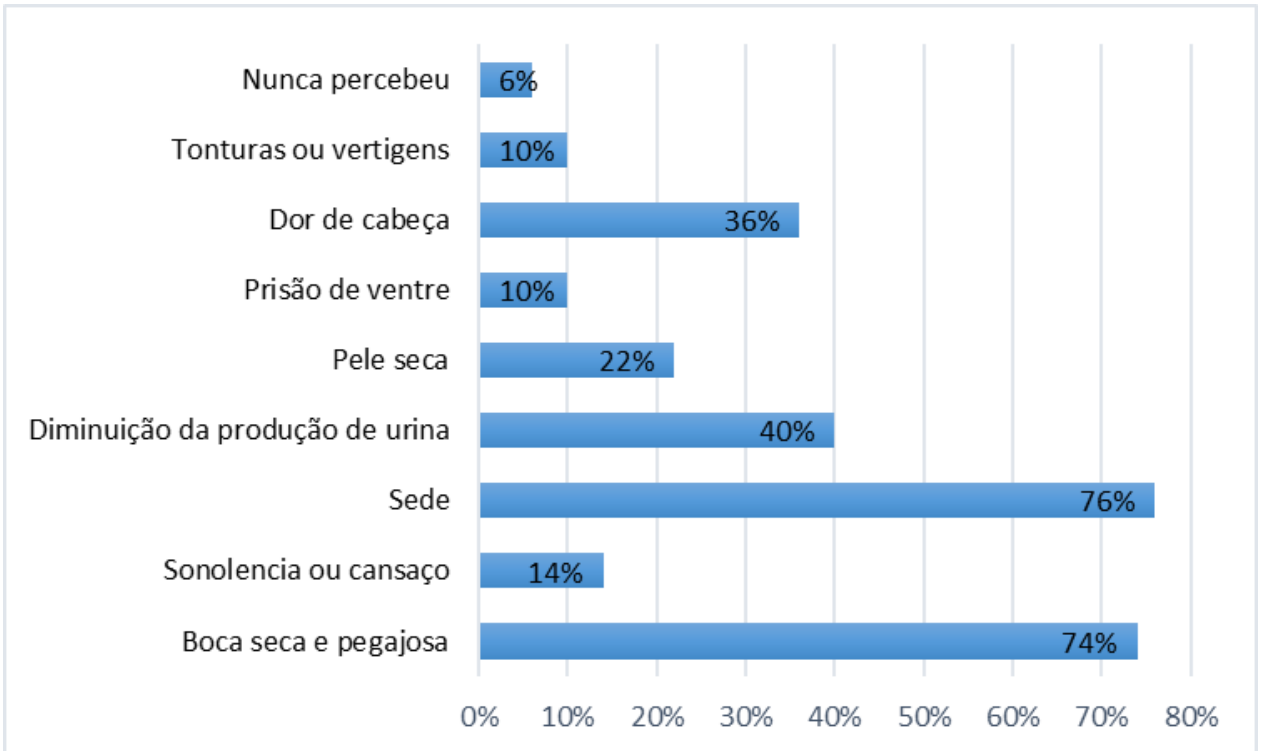

Fonte: Brito NP, et al., 2021.

Por meio do último quesito do questionário metodológico "O que você sabe sobre os benefícios da água no corpo?", avaliamos o conhecimento dos estagiários entrevistados sobre os efeitos benevolentes da água no organismo, de modo que as variadas respostas obtidas puderam ser enquadradas em basicamente cinco núcleos de resposta, quais sejam: "promove hidratação da pele e demais órgãos", "importante para o bom funcionamento do corpo", "melhora metabolismo e eliminação de toxinas", "melhora função renal e evita problemas como pedra nos rins" e "integra a maior parte da constituição do corpo". A quantificação das respostas de acordo com os núcleos onde foram enquadradas (Tabela 1).

Tabela 1 - Avaliação do nível de conhecimento de hábitos de hidratação por núcleo de resposta, 2021

Variável $\quad$ N $\%$

\section{Núcleo de Resposta}

$\begin{array}{lcc}\begin{array}{l}\text { Promove hidratação da pele e demais órgãos } \\ \text { Importante para o bom funcionamento do corpo e } \\ \text { dos sistemas }\end{array} & 29 & 47,54 \\ \begin{array}{l}\text { Melhora metabolismo, circulação e elimina toxinas } \\ \text { Melhora função renal e evita problemas como }\end{array} & 5 & 27,86 \\ \quad \text { pedra nos rins e desidratação } & 5 & 8,19 \\ \text { Integra a maior parte da constituição do corpo } & 5 & 8,19\end{array}$

Fonte: Brito NP, et al., 2021. 
Deve-se destacar que houve respostas emitidas por estudantes que se encaixaram em mais de um núcleo de resposta, conforme cita-se: Das 29 respostas do Núcleo "Promove hidratação da pele e demais órgãos", 5 também se encaixaram no núcleo "Importante para o bom funcionamento do corpo e dos sistemas", outras 3 no núcleo "melhora metabolismo, circulação e elimina toxinas" e outras 3 no núcleo "integra a maior parte da constituição do corpo".

Ficando assim justificado a incompatibilidade do somatório da quantificação de resposta ser 61 e o espaço amostral de entrevistados e, portanto, de respostas obtidas ser 50 . Importante destacar ainda que algumas respostas obtidas não foram incluídas nos núcleos por não possuírem correspondência com os respectivos, tais como: "faz bem para tudo", "é o melhor líquido para beber" e "evita dor de cabeça".

Conforme os resultados obtidos, através da aplicação de questionários foi possível observar em relação a essa temática, que ainda existe certa insegurança e poucas informações por parte dos estudantes em relação a importância e benefícios de um bom nível de hidratação bem como dúvidas sobre a importância da hidratação e com isso, o grupo iniciou uma reflexão sobre as possíveis intervenções a serem realizadas para conscientizar e orientar sobre a ingesta importância da ingesta hídrica na população estudada.

Com base nesta observação, em reunião com orientadores da disciplina, ocorreu a apresentação dos resultados e em conjunto com os dados obtidos, pensou-se em realizar uma estratégia de intervenção para incentivar a ingesta hídrica e para isso uma proposta de educação em saúde foi a disseminação de materiais impressos e educativos, que mostrou ser uma opção viável e segura para ser feita no atual cenário de pandemia pelo novo Coronavírus.

Durante as primeiras reuniões para debate sobre os resultados, ocorreu a discussão sobre a possibilidade de intervenção com o grupo avaliado (estagiários de odontologia) e no primeiro momento considerou a criação de um Gibi ilustrativo onde o personagem principal sanaria dúvidas sobre hidratação no decorrer da história, porém ao refletir sobre o público-alvo e o momento em que se encontram (último ano da graduação com estágios e trabalho de conclusão de curso), e da possibilidade de não aderência do gibi ao público-alvo ocorreu nova reunião em grupo e optou-se pela criação de um flyer Informativo, por ser de fácil disseminação e rápida leitura.

O flyer proposto foi desenvolvido com o intuito de divulgar sobre a importância da hidratação e seus benefícios. Sendo elaborado na plataforma do editor Canva, em um tamanho A4 com a sua impressão feita em papel sulfite. Além disso nele consta o título/tema que é centrado na temática da hidratação, com intuito de destacar o tema e gerar curiosidade no público-alvo.

Consta também imagens com o objetivo de chamar atenção do público e ilustrações condizentes com o texto que acompanham. Importante salientar que o flyer foi pensado e elaborado pensando em sanar as dúvidas e em cima os pontos mais importantes encontrados na presente pesquisa sendo estes distribuídos na clínica escola de odontologia, local onde ocorre os estágios do curso de odontologia e em pontos de grande circulação na campus como biblioteca, refeitório e recepção.

Para a organização de informações, o resultado dos questionários aplicados foi imprescindível, visto que, tornou-se possível reunir e observar quais os tópicos mais relevantes para compor os textos abordados no flyer, sendo eles: Quantidade de líquidos necessária, tipo de líquido, cuidados necessários, benefícios e sintomas da desidratação.

Diante disso, a disponibilização de flyers contendo informações importantes e dicas para os estudantes no ambiente institucional, pode vir a ser capaz de difundir e contribuir para uma conscientização acerca dos pontos levantados na pesquisa (Figura 1). 
Figura 1- Flyer utilizado na intervenção após análise dos dados do presente artigo, contendo orientações sobre o uso adequado de água no decorrer do dia, 2020.

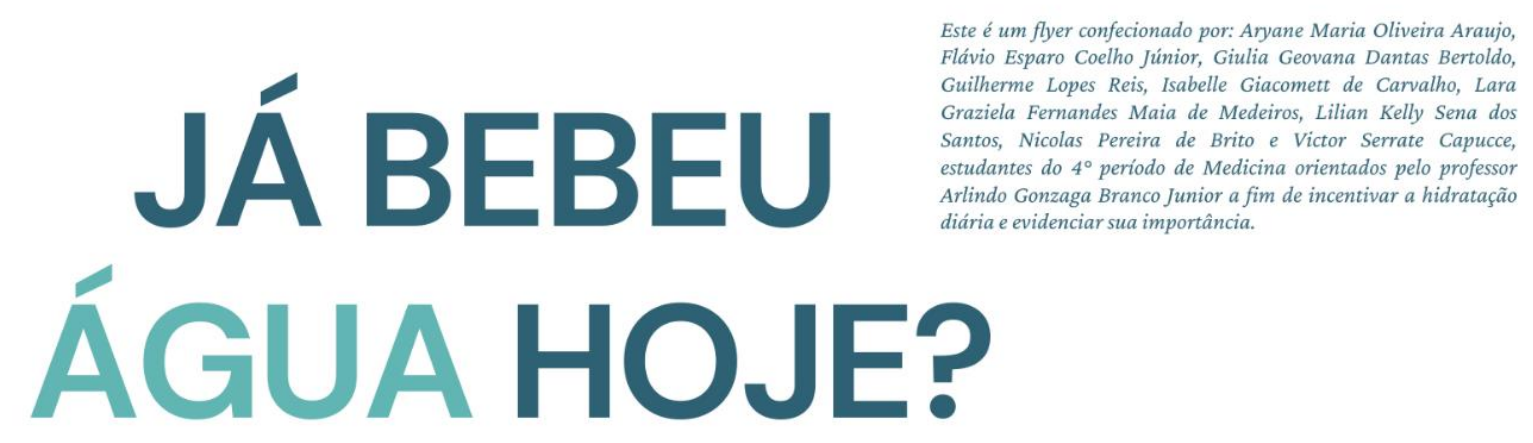

\section{QUANTIDADE:}

2 LITROS DE ÁGUA POR DIA.

*Valor estipulado pelo Ministério da Saúde podendo sofrer alteração de acordo com Idade, peso, clima, temperatura e atividade física.

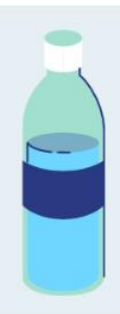

\section{PORQUE BEBER ÁGUA PURA?}

Além de ser a fonte mais adequada de hidratação, pois é livre de aditivos e açúcares, é somente na presença de água potável que funções como a de diminuição do riscos de pedra nos rins e de oxidação da gordura se tornam possíveis. Por isso sempre prefira água pura a outras bebidas calóricas.

\section{MALEFÍCIOS DA DESIDRATAÇÃO:}

- Podem produzir perturbações de humor (leve);

- Prejudica o desempenho em tarefas como memória de curto prazo (leve a moderada)

- Pode ser fator de risco para delirium manifestado como demência em idosos e pessoas muito doentes.

\section{DICAS!}

- NÃO ESPERE SENTIR SEDE! A sede é o primeiro sinal de que você já está desidratado;

- MANTENHA UMA GARRAFINHA DE ÁGUA NA BOLSA, dessa forma, fica mais difícil esquecer e pode ser consumida com frequência;

- EXISTEM APLICATIVOS QUE FUNCIONAM COMO LEMBRETES, dessa forma, você pode configurar de acordo com seus horários;

Fonte: Brito NP, et al., 2021.

\section{CUIDADO!}

Beber quantidades de água em excesso e de uma vez só, faz mal, pode sobrecarregar os rins e provocar perda das reservas de sódio no sangue. Dessa forma, não tente atingir o consumo diário de uma só vez, consuma aos poucos e ao longo do dia.

\section{BENEFÍCIOS DA HIDRATAÇÃO:}

- Diminuição do risco de Doenças Renais Crônicas;

- Minimiza a mortalidade cardiovascular;

- Previne a hiperglicemia;

- Preserva o bom metabolismo.

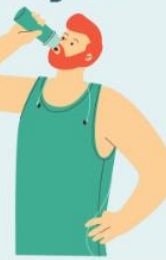

SINAIS DE DESIDRATAÇÃO:

- Mucosas secas (boca, nariz, sulcos longitudinais da língua);

- Prejuízo no desempenho físico (fraqueza);

- Perda de funções cognitivas;

- Incoerência da fala;

- Olhos fundos.

\section{REFERÊNCIAS:}

- BRASIL. Ministério da Saúde. Guia alimentar para a população brasileira. 2014. Disponível em:

https://bvsms.saude.gov.br/bvs/publicacoes/guia_alimentar_populaca o_brasileira_2ed.pdfAcesso em: 24 out. 2020.

- JÉQUIER E, CONSTANT F. Water as an essential nutrient: the physiological basis of hydration. European Journal of Clinical Nutrition. 2010;64(2):115-123.

- LISKA D, et al. Narrative Review of Hydration and Selected Health Outcomes in the General Population. Nutrients, 2019; 11(1):70

- POPKIN B, et al. Water, hydration, and health. NutritionReviews, 2010; 68(8): 439-458.

- PERRIER E. Shifting Focus: From Hydration for Performance to Hydration for Health. Annals of Nutrition \& Metabolism, 2017; 1:4-12. 


\section{DISCUSSÃO}

Ao analisar os dados coletados, abstrai-se que o alunado feminino na referida instituição é de $62 \%$, índice que supera a presença feminina nas instituições federais de ensino superior do país, que corresponde a $54,6 \%$ (FONAPRACE, 2019). Ainda, segundo o mesmo autor, a média de idade obtida é exatamente a mesma da educação superior federal, haja vista a média de 24 anos de idade no levantamento realizado em 2018, assim como o realizado nesta pesquisa. A partir dos dados de peso e altura coletados no questionário, determinou-se as porcentagens de Índice de Massa Corporal dos participantes, sendo $44 \%$ destes classificados como normal, de modo que outros $44 \%$ apresentam sobrepeso ou mesmo obesidade, deve-se assinalar que, segundo a Organização Mundial da Saúde (2004), a quantidade de água a ser consumida aumenta proporcionalmente com o peso do indivíduo.

Em relação à ingesta de água dos alvos da pesquisa, $50 \%$ dos estagiários alegaram beber menos de dois litros do líquido por dia. Todavia, segundo a Organização Mundial da Saúde (2004) este índice está abaixo do ideal, já que, o mínimo de ingestão de água para reposição hidroeletrolítica diária é de 3 litros para um indivíduo adulto e pode ser ainda maior dependendo do clima da região. Não somente a quantidade é irregular, também há irregularidade nos intervalos do consumo, já que $42 \%$ do $\mathrm{N}$ amostral espera pelo menos 3 horas entre os momentos de reposição hídrica, assim, quando não se repõe água, a desidratação ocorre, e com isso, mecanismos fisiológicos são ativados no corpo e geram a sede (ASHCROFT FM, 2001).

De acordo coletado, $74 \%$ dos entrevistados relatam que se deve ingerir água antes do mecanismo de sede aparecer. Esse resultado demonstra que os participantes da pesquisa estão seguindo a recomendação correta, pois a sede se manifesta apenas quando o organismo já se encontra em desequilíbrio, devido a maior concentração de sódio plasmático (FURTADO CM, et al., 2009).

Esse hábito de hidratação preventivo evita a desidratação, no entanto, de acordo com os resultados obtidos na pesquisa, os motivos mais relatados para o esquecimento foram relacionados a grande carga de trabalho ou pouco tempo de pausa, pois a hidratação preventiva falha e os estagiários de odontologia são lembrados de ingerir líquidos apenas quando surge a sede. Ao abordar qual o líquido mais ingerido, 92\% das respostas foi água, que é o líquido mais indicado, devido à sua maior pureza, no que se refere à ingestão de sódio, açúcares e calorias. Em relação aos outros tipos de bebidas, como sucos e refrigerantes, além de altas proporções calóricas, há também elevadas concentrações de sódio (SALAS-SALVADÓ J, et al., 2020).

Ainda segundo o mesmo autor, deve-se aumentar a ingestão de líquidos nos dias mais quentes e/ou secos, todavia os estagiários de odontologia não relataram isso em suas respostas. Aprofundando a análise, notase que os estudantes passam a maior parte do dia em ambientes fechados e climatizados, o que interfere na percepção das alterações de temperatura. São sinais clássicos da desidratação leve e moderada, a sede exagerada, boca e pele secas, olhos fundos, ausência ou pequena produção de lágrimas e diminuição da sudorese. Uma sensação de sede mais excessiva já é sinal do cérebro indicando a necessidade de reabastecer os níveis de fluídos no corpo para manter todas as funções (ROSSI L, 2010).

Os dados colhidos na pesquisa apontam dois sintomas mais comuns que são apresentados durante períodos com pouca ingestão de líquidos, sede (76\%) e boca seca e pegajosa (74\%), entre outros sintomas mostrado no gráfico 3. O fenômeno pode ser explicado pelo autor supracitado, o qual afirma que beber água é que lubrifica a mucosa da boca e da garganta, ingerir muita água filtrada ou fervida em goles pequenos e intervalos curtos pode ser o suficiente para reidratar o organismo.

É correto afirmar que água é essencial para a vida, por causa de suas inúmeras e diversas funções no corpo, muitas vezes é considerado o nutriente mais importante. A água constitui a maior parte do peso do nosso corpo, podendo variar de 45 a $75 \%$ deste peso, a depender da idade e sexo, sendo considerado em média $60 \%$ para adultos. Os alvos da pesquisa foram abordados com a seguinte pergunta "o que você sabe sobre os benefícios da água no corpo?", mais de $50 \%$ das respostas podemos ver que estão corretas, porém superficiais em relação a seus importantes benefícios. Outro ponto relevante é que a água contém substâncias dissolvidas, auxiliando na manutenção do equilíbrio eletrolítico e da osmolaridade. Os mais 
importantes solutos presentes nos líquidos corporais são os sais (principalmente, o sódio, cloreto, fosfatos e sais proteinados) e quantidades variáveis de cálcio, magnésio e potássio (SOCIEDADE BRASILEIRA DE ALIMENTAÇÃO E NUTRIÇÃO, 2016).

Quanto a intervenção, necessário pensar em uma prática de educação em saúde respeitando as questões de isolamento social e medidas restritivas devido ao Novo Coronavírus, evitando assim a disseminação do mesmo. Neste interim, Silva JN, et al., (2020) realizou uma prática de educação em saúde com flyers na mesma instituição de ensino em um ambulatório escola sendo então este pensamento adotado pelo grupo para a realização da intervenção na população estudada.

\section{CONCLUSÃO}

Apesar da demonstração de conhecimento de grande parte dos pesquisados acerca da importância e dos benefícios de se manter hidratado ao longo do dia, a grande parcela da amostra não realiza o consumo de líquidos de forma adequada, seja pela baixa ingesta ou pelo grande intervalo de tempo entre eles. Nesse sentido, faz-se necessário pesquisas voltadas para promoção de saúde e incentivo a ingesta de água de forma adequada e que não acarrete em malefícios para o estagiário.

\section{REFERÊNCIAS}

1. ASHCROFF FM. A vida no Limite: A Ciência da Sobrevivência. Rio de Janeiro: Editora Zahar, 2001; 316p.

2. BRASIL. Ministério da Saúde. Guia alimentar para a população brasileira. 2014. Disponível em: https://bvsms.saude.gov.br/bvs/publicacoes/guia_alimentar_populacao_brasileira_2ed.pdf. Acesso em: 24 out. 2020.

3. CARVALHO APL, ZANARDO VPS. Consumo de água e outros líquidos em adultos e idosos residentes no município de Erechim - Rio Grande do Sul. Perspectiva, 2010; 34(125): 117-126.

4. CRUZ MAE, et al. Nível de conhecimento e hábitos de hidratação dos atletas de mountain bike. Fitness Perfomance Journal. 2009; 8(2):79-89.

5. DAVANZO GG, et al. [Des]-[re]-[hiper]-hidratação. Revista Brasileira de Fisiologia do Exercício, 2015; 14(2): $104-113$.

6. FONAPRACE. V Pesquisa Nacional de Perfil Socioeconômico e Cultural dos Graduandos das IFES. 2019. Disponível em: https://www.andifes.org.br/wp-content/uploads/2019/05/V-Pesquisa-Nacional-de-PerfilSocioecon\%C3\%B4mico-e-Cultural-dos-as-Graduandos-as-das-IFES-2018.pdf. Acesso em 24 out. 2020.

7. FURTADO CM, et al. Avaliação de hábitos e conhecimentos sobre hidratação de praticantes de musculação de uma academia da cidade de São Paulo. Educación Física y Deportes. 2009; 14(133):1.

8. INSTITUTO DE HIDRATAÇÃO E SAÚDE. Conselho Científico do Instituto de Hidratação e Saúde. Estabelecimento de recomendações de hidratação para os portugueses. 2010 . Disponível em: http://www.ihs.pt/xms/files/newsletter_5/ESTABELECIMENTO_DAS_RECOMENDACOES_DE_HIDRATACAO_PA RA_OS_PORTUGUESES.pdf. Acesso em 24 out. 2020

9. JÉQUIER E, CONSTANT F. Water as an essential nutrient: the physiological basis of hydration. European Journal of Clinical Nutrition. 2010;64(2):115-123.

10. LISKA D, et al. Narrative Review of Hydration and Selected Health Outcomes in the General Population. Nutrients, $2019 ; 11(1): 70$.

11. PERRIER E. Shifting Focus: From Hydration for Performance to Hydration for Health. Annals of Nutrition \& Metabolism, 2017; 1:4-12.

12. POPKIN B, et al. Water, hydration, and health. Nutrition Reviews, 2010; 68(8): 439-458.

13. RONDÔNIA. Diário Oficial do Estado de Rondônia. 2020. Disponível em: http://www.diof.ro.gov.br/data/uploads/2020/03/DOE-16.03.2020.pdf. Acesso em: 20 jan. 2021.

14. ROSADO C, et al. Importancia del agua en la hidratación de la población española: documento FESNAD 2010. Nutrición Hospitalaria, 2011; 26(1):27-36.

15. ROSSI L, et al. Desidratação e recomendações para a reposição hídrica em crianças fisicamente ativas. Revista Paulista de Pediatria, 2010; 28(3), 337-345.

16. SALAS-SALVADÓ J, et al. Importancia del consumo de agua en la salud y la prevención de la enfermedad: situación actual. Nutrición Hospitalaria. 2020; 37(5):1072-1086.

17. SHIRREFFS SM. Markers of hydration status. European Journal of Clinical Nutrition, 2003; 57(2): 6-9.

18. SILVA JN, et al. Exame de papanicolaou: conhecimentos de mulheres em uma unidade de saúde escola da Amazônia ocidental. Revista Eletrônica Acervo Saúde, 2020; 12(7), e3312.

19. SOCIEDADE BRASILEIRA DE ALIMENTAÇÃO E NUTRIÇÃO. Água, hidratação e saúde. 2016. Disponível em: http://sban.cloudpainel.com.br/source/Agua-HidrataAAo-e-SaAde_Nestle_.pdf. Acesso em: 24 out. 2020.

20. TORTORA GJ, DERRICKSON B. Princípios de anatomia e fisiologia. 12ª edição. Rio de Janeiro: Guanabara Koogan, 2010; $1216 p$. 